\title{
Rupture of a renal angiomyolipoma (hamartoma)
}

\author{
M. StavorovsKY \\ M.D. \\ B. MORAG \\ M.D. \\ D. IRGE \\ E. SCHUJMAN* \\ M.D. \\ M.D.

\begin{abstract}
*Department of General and Vascular Surgery and Pathological Institute, Municipal-Governmental Medical Center Tel-Aviv/Yaffo, Ichilov Hospital and Tel-Aviv University Sackler School of Medicine, Tel-Aviv, Israel
\end{abstract}

\begin{abstract}
Summary
A 54-year-old woman with spontaneous rupture of angiomyolipoma is presented. The literature on the 2 types of angiomyolipoma, without and with association of tuberose sclerosis, their rarity and the difficulties in their diagnoses, is reviewed.
\end{abstract}

\section{Introduction}

Angiomyolipoma (hamartoma) of the kidney is a rare finding. Hajdu and Foote (1969) recorded an incidence of $0.31 \%$ in 8501 post-mortem cases. McCullough, Scott and Seybold (1971), Becker et al. (1973), Honey and Honey (1977) consider that $50-80 \%$ of renal hamartomas appear in patients with tuberose sclerosis. Angiomyolipomas without tuberose sclerosis are usually solitary and unilateral. Rupture may be a complication in $4.5 \%$ of the solitary angiomyolipomas (Vasko, Brockman and Bomar, 1965).

To the author's knowledge, only 9 rupture cases have been reported (Vasko et al., 1965; Wapnik et al., 1975). An additional case is now presented which was diagnosed intra-operatively.

\section{Case report}

A 54-year-old woman was admitted with acute abdominal pains of $8 \mathrm{hr}$ duration accompanied by vomiting. The pain radiated to the back and right lower abdomen. Over the past 2 years the patient had lost approximately $30 \mathrm{~kg}$ and had recurrent episodes of atrial fibrillation. On admission she was pale and sweating with a blood pressure of $90 / 60$ $\mathrm{mmHg}$ and sinus tachycardia of $124 / \mathrm{min}$. Exophthalmos was marked and an enlarged thyroid was palpable. There were decreased breath sounds at the left base. There was rebound tenderness and guarding in the right abdomen. The patient's $\mathrm{Hb}$ was 10.5 $\mathrm{g} / \mathrm{dl}$ with a haematocrit of $21 \%$. The leucocyte count was $20 \cdot 7 \times 10^{9} / 1$, platelet count $110 \times 10^{9} / 1$. Glucose, urea, diastase, prothrombin and urine

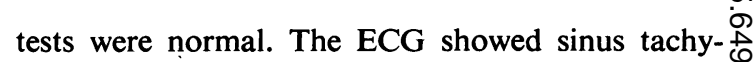
cardia. A plain abdominal X-ray revealed absence $\circ$ of the right psoas shadow. The IVP was normal but $f$ the right kidney was displaced upwards by a retro- $ᄋ$ peritoneal mass which caused an area of depletion in the lower pole. Despite blood and electrolyte $z$ transfusion, the patient's condition deteriorated. Her blood pressure dropped to $75 / 70 \mathrm{mmHg}$ and $\stackrel{\mathbb{}}{3}$ the pulse rate rose to $140 / \mathrm{min}$. Therefore, an urgent laparotomy was performed under general anesthesia. Fresh blood was found in the abdominile

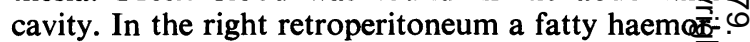
rhagic necrotic mass was detected attached to the kidney and the suprarenal gland, all surrounded by blood clot. The bleeding was controlled. The right kidney with the attached necrotic fatty mass and suprarenal gland was removed. Excluding $\stackrel{\odot}{\mathscr{\perp}}$ episodes of atrial fibrillation, the postoperative $\overrightarrow{\vec{F}}$ period was uneventful. Endocrinological investiga- $\frac{0}{3}$ tions, including elevated T3, T4 and high value of the ${ }^{131}$ I uptake, indicated hyperthyroidism. The patient was discharged in good condition and advised to receive further treatment with carbimazole. 3 Following appropriate treatment for 6 months, her general condition improved and she gained $8 \mathrm{~kg}$. At follow-up, no neurological or X-ray signs $\stackrel{\bigcirc}{\mathrm{O}}$ of tuberose sclerosis were observed.

\section{Histology}

The kidney weighed $380 \mathrm{~g}$. At the lower pole a을 spherical, lobulated yellowish-grey tumour of $8 \mathrm{~cm}$ in diameter was found (Fig. 1). No capsule was. apparent on gross inspection. The cut section $N$ disclosed extensive foci of haemorrhagic discoloration and areas of softening. Microscopically, the tumour was highly cellular and composed of main components (Fig. 2): areas of typical vacuolated $\frac{\Phi}{\Phi}$ adult fat cells, demonstrable only by the thin rim $\stackrel{\rho}{?}$ of cell membrane separating them from adjacent 0 cells; spindled smooth muscle cells; and numerous 


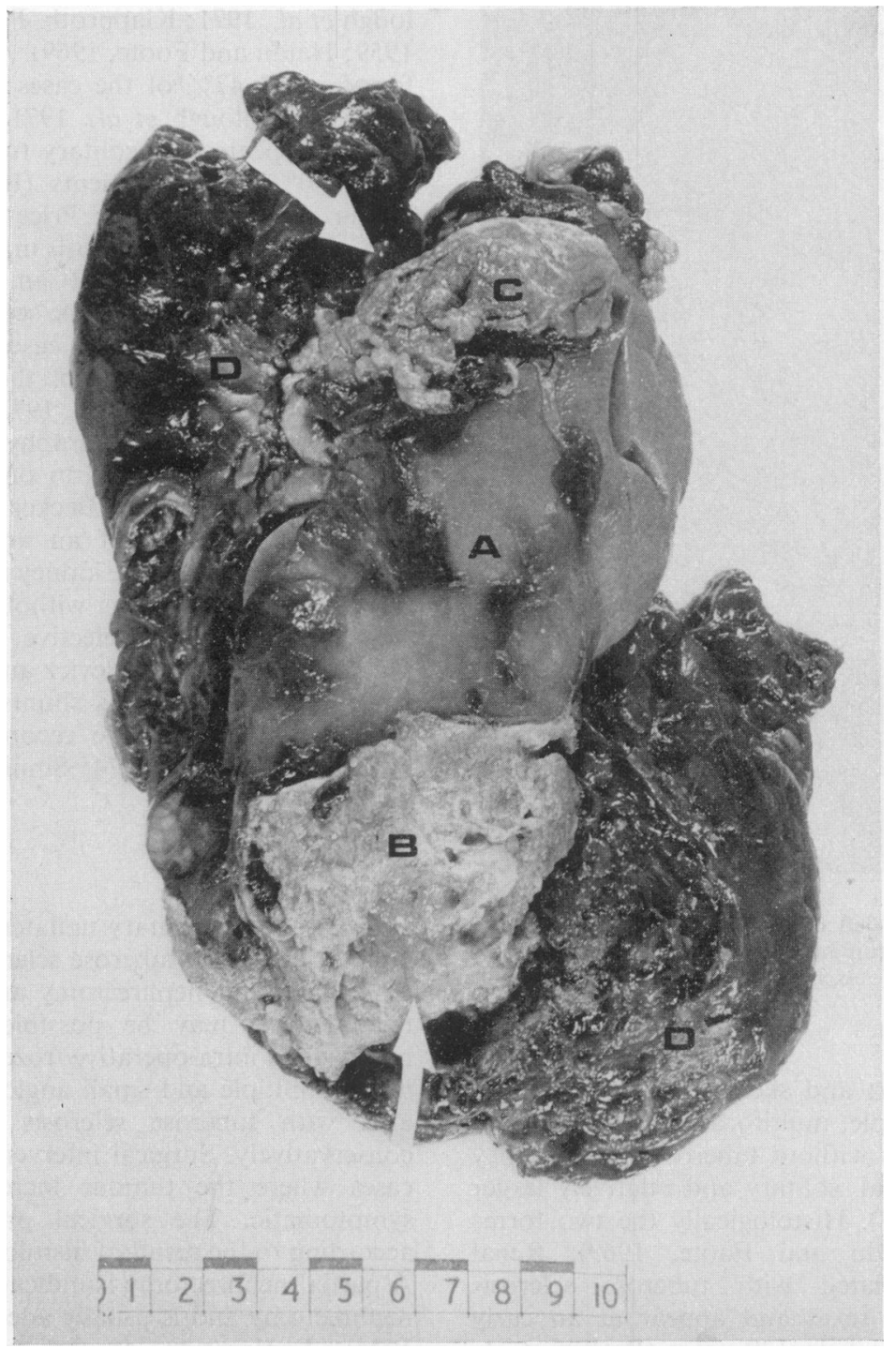

FIG. 1. Right nephrectomy specimen: A, kidney; B, attached angiomyolipoma; C, suprarenal gland; D, haemorrhagic perirenal adipose tissue.

thick walled, tortuous blood vessels surrounded by large numbers of smooth muscle cells which extended into the fat tissue. The tumour was sharply demarcated from the adjacent renal tissue. Vascular invasion was not found.

\section{Discussion}

Renal hamartoma is a mesenchymal tumour composed of a mixture of blood vessels, smooth muscle and adipose tissue in varying proportions; thus the name angiomyolipoma. Tuberose sclerosis associated with renal hamartomas was first described by Bourneville in 1880 (Vasko et al., 1965). It is caused by an autosomal dominant hereditary gene and is characterized by epilepsy, mental retardation and skin manifestation (adenoma sebaceum cyst). According to various authors, $50-80 \%$ of patients with tuberose sclerosis have additional renal hamartomas (McCullough et al., 1971 ; Becker et al., 1973; Honey and Honey, 1977).

Hamartomas associated with tuberose sclerosis are often found in various organs; chiefly in the 


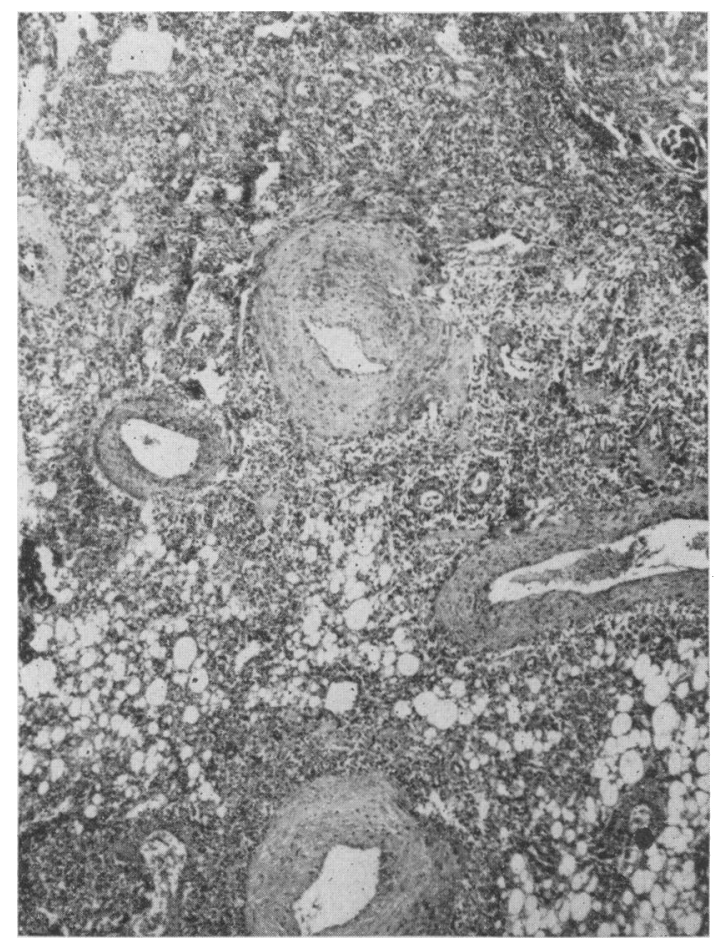

Fig. 2. Renal tissue (left upper corner) and the 3 main components of the tumour are seen: mature fat cells, thick walled blood vessels and smooth muscle fibres $(\mathrm{HE}, \times 24)$.

kidneys, chest, heart and skeletal bones. They are mostly small, multiple, multifocal and involve both kidneys. In patients without tuberose sclerosis they are usually unilateral, solitary and relatively larger (Becker et al., 1973). Histologically the two forms are identical (Hajdu and Foote, 1969). Renal hamartomas associated with tuberose sclerosis are found in both sexes and appear at an early age, the average age being 30 years (Becker et al., 1973). Renal hamartomas which are not associated with tuberose sclerosis appear at an average age of 48 years and are more common in women with a ratio of $23: 4$ (Becker et al., 1973; McCullough et al., 1971).

Seabury, Ensor and Wolfe (1967) compiled from the literature 150 cases of angiomyolipomas without tuberose sclerosis. Vasko et al. (1965) discovered that $15.3 \%$ of the cases were symptomatic.

The diagnosis of angiomyolipoma is difficult. Pain, haematuria, a palpable mass and continuous fever assist the diagnosis. However, when bleeding and signs of an acute abdomen appear, the diagnosis is quite impossible. The main complaint is flank pain which is found in $73.7-91.3 \%$ of the cases (McCul- lough et al., 1971; Klapproth, Poutasse and Hazard, ڤ 1959; Hajdu and Foote, 1969). A palpable mass was found in $33-47 \%$ of the cases (Price and Mostofi, $\stackrel{\Omega}{\square}$

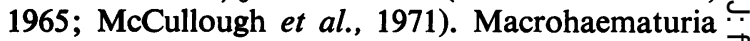
usually appears with solitary tumours and is found $\overrightarrow{\vec{s}}$ in $16-40 \%$ of the patients (Becker et al., 1973; Hajdu and Foote, 1969; Price and Mostofi, 1965; 든 McCullough, 1974). Necrosis in the hamartoma may $\frac{\bar{\sigma}}{2}$ result in continuous fever (Campbell et al., 1974).

A fatty mass which can be seen in a plain abdom- 응 inal X-ray is, in $9 \%$ of cases, suggestive of an angiomyolipoma. In $6 \%$ of the cases calcification $\overrightarrow{0}$ can be found (Becker et al., 1973); IVP, sonography $\overrightarrow{\vec{H}}$ and selective renal angiography are not sufficiently diagnostic and may confirm only that this mass is not cystic (Lee, 1977; Becker et al., 1973). The $\frac{0}{3}$ differential diagnosis of an angiomyolipoma and malignant tumour of the kidney is difficult. However, on 26 cases of hamartomas without tuberose sclerosis $\stackrel{+}{\oplus}$ were diagnosed by selective renal angiography (McCallum, 1975; Smulevicz and Fafreshi, 1977) in ${ }_{0}$ which no arterio-venous shunts were found. False $\circ$ negative diagnoses were recorded (Becker et al., 1973; McCullough, 1974; Smulewicz and Fafreshi, $z$ 1977).

\section{Treatment}

In cases of a solitary unilateral angiomyolipond $\vec{\theta}$ unassociated with tuberose sclerosis, removal of the mass and total nephrectomy are indicated. Partiâ. nephrectomy may be possible according to the histology of intra-operative frozen section. Asymptomatic, multiple and small angiomyolipomas associated with tuberose sclerosis should be treated $\stackrel{\circ}{\odot}$

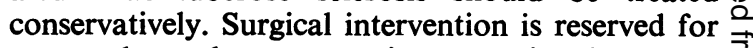
cases where the tumour increases in size or is symptomatic. The surgical procedure should be according to the result of histological frozen section. A partial nephrectomy is indicated rather than total nephrectomy and is usually adequate (McCullough, $\frac{0}{3}$ 1974). Exploration of the retroperitoneum and frozen section study of the mass is indicated when 3 malignancy is suspected. Ruptured angiomyolipoma, as in the case presented, requires total nephrectomy and removal of the attached fatty $\mathrm{O}$ mass.

\section{References}

Becker, J.A., Kinkhabwala, M., Ollack, H. \& Bosniak, M. (1973) Angiomyolipoma of the kidney. Acta radiologica, $\mathrm{O}$ 14,561 .

Campbell, E.W., Brantley, R., Harrold, M. \& Simson, L.R. (1974) Angiomyolipoma presenting as fever of unknown origin. American Journal of Medicine, 57, 843.

HAJDU, S.I. \& FOOTE, F.W. (1969) Angiomyolipoma of the $\mathbb{D}$ kidney: Report of 27 cases and review of literature. Journal of Urology, 102, 396.
.

.

$842 \quad$ Case reports 
Honey, R.J. \& HoNeY, R.M. (1977) Tuberose sclerosis and bilateral renal carcinoma. British Journal of Urology, 49, 441.

Klapproth, H.S., Poutasse, E.F. \& Hazard, J.B. (1959) Renal angiomyolipomas. Archives of Pathology, 67, 400.

LEE, W.J. (1977) Angiographic manifestations of renal hamartoma. Angiology, 28, 416.

MCCAllum, R.W. (1975) The pre-operative diagnosis of renal hamartoma. Clinical Radiology, 26, 257.

McCullough, D.L., Scotr Jr, R. \& Seybold, H.M. (1971) Renal angiomyolipoma (hamartoma). Journal of Urology, $105,32$.

McCullough, D.L. (1974) Renal hamartoma, current of diagnosis and surgical management. Urology, 4, 235.
Price, E.B. \& Mostofi, F.K. (1965) Symptomatic angiomyolipoma of the kidney. Cancer, 18, 761.

Seabury, J.C., Ensor, R.D. \& Wolfe, W.G. (1967) Angiomyolipoma of the kidney: A benign tumor demonstrating neo-vascularization of arteriography. Journal of Urology, 98, 562.

SMULEWICZ, J.J. \& FAFRESHI, M. (1977) Angiographic changes in tuberous sclerosis. Angiology, 28, 300.

WAPNIK, M.S., LAZARovicI, I., BARATZ, M. \& SolowieczyK, M. (1975) Spontaneous rupture of an angiomyolipoma of the kidney. International Journal of Surgery, 60, 485.

VASKo, J.S., BRockmaN, S.K. \& Bomar, R.L. (1965) Renal angiomyolipoma: A rare cause of spontaneous massive retroperitoneal hemorrhage. Annals of Surgery, 161, 577. 